\title{
ABUSO SEXUAL NA INFÂNCIA: POTENCIAL DA NARRATIVA NA VIVÊNCIA DE CRIANÇA
}

MILENE GABRIELA WINCK

https:/ /orcid.org/0000-0001-7420-7299

Universidade Federal do Mato Grosso

DANIELA BARROS DA SILVA FREIRE ANDRADE

https://orcid.org/0000-0002-7861-3814

Universidade Federal do Mato Grosso

RESUMO O presente artigo refere-se a um estudo de caso e tem como objetivo principal analisar a construção de sentidos por uma criança vítima de abuso sexual. 0 estudo traz contribuições da perspectiva histórico-cultural, em articulação com a teoria das representações sociais e estudos sobre narrativa. Objetiva-se investigar o potencial da narrativa enquanto atividade-guia capaz de suscitar processos terapêuticos, mediação no contexto da hospitalização de crianças e atuar na iminência de processos de significação. 0 procedimento metodológico adotado foi inspirado nos estudos microgenéticos e compreendeu a realização de encontros psicoterapêuticos individuais e em grupo. Os mesmos priorizaram a mediação em contexto lúdico e encorajador da produção de narrativas pela criança. As notas de campo foram analisadas compreensivamente a partir da definição de episódios de acordo com o conteúdo semântico, recorrência e a carga afetiva empreendida nos processos comunicacionais. Os dados revelaram que narrativas preexistentes no ambiente hospitalar e amplamente socializadas no âmbito do acolhimento a crianças hospitalizadas são internalizadas e recriadas pela criança, estas ainda podem atuar na iminência da elaboração das suas vivências mais intimas e suscitar processos de metaforização espontânea.

Palavras-chave: Abuso sexual infantil. Narrativa. Significação.

\section{ABSTRACT SEXUAL ABUSE IN CHILDHOOD: POTENTIAL OF NARRATIVE IN A CHILD'S EXPERIENCE}

This article refers to a case study and its main objective is to analyze the construction of meanings by a child victim of sexual abuse. The study brings contributions from the Historical-Cultural perspective, in 
conjunction with the theory of social representations and studies on narrative. The objective is to investigate the potential of the narrative as a guide activity capable of eliciting therapeutic processes, mediation in the context of children's hospitalization and acting on the imminence of meaning processes. The methodological procedure adopted was inspired by microgenetic studies and comprised individual and group psychotherapeutic meetings. They prioritized mediation in a playful and encouraging context for the production of narratives by the child. The field notes were analyzed comprehensively from the definition of episodes according to the semantic content, recurrence and the affective load undertaken in the communication processes. The data revealed that pre-existing narratives in the hospital environment and widely socialized in the context of welcoming hospitalized children are internalized and recreated by the child, they can still act on the imminence of the elaboration of their most intimate experiences and raise spontaneous metaphorization processes.

Keywords: Child Sexual Abuse. Narrative. Meaning.

\section{ABUSO SEXUAL EN LA INFANCIA: POTENCIAL DE LA NARRATIVA EN LA EXPERIENCIA DE UN NIÑO}

El presente artículo se refiere a un estudio de caso y su objetivo principal es analizar la construcción de significados por un niño víctima de abuso sexual. El estudio aporta contribuciones desde la perspectiva histórico-cultural, junto con la teoría de las representaciones sociales y los estudios sobre la narrativa. El objetivo es investigar el potencial de la narrativa como una actividad de guía capaz de provocar procesos terapéuticos, mediación en el contexto de la hospitalización de niños y actuar sobre la inminencia de procesos de significado. El procedimiento metodológico adoptado se inspiró en estudios microgenéticos y comprendió reuniones psicoterapéuticas individuales y grupales. Priorizaron la mediación en un contexto lúdico y alentador para la producción de narraciones por parte del niño. Las notas de campo se analizaron exhaustivamente a partir de la definición de episodios según el contenido semántico, la recurrencia y la carga afectiva emprendida en los procesos de comunicación. Los datos revelaron que las narraciones preexistentes en el entorno hospitalario y ampliamente socializadas en el contexto de acoger a niños hospitalizados son internalizadas y recreadas por el niño, aún pueden actuar sobre la inminencia de la elaboración de sus experiencias más intimas y generar procesos espontáneos de metaforización.

Palabras clave: Abuso Sexual Infantil. Narrativa. Significado. 


\section{Introdução}

0 presente artigo refere-se a um estudo de caso ${ }^{1}$ que buscou analisar o processo de elaboração psíquica de uma criança, vítima de abuso sexual, no âmbito do atendimento psicoterápico desenvolvido no Hospital Universitário Júlio Müller (HUJM), da Universidade Federal do Mato Grosso (UFMT), por meio do projeto de extensão Rede de Apoio à Infância: interfaces com a Psicologia e a Pedagogia, subprojeto Binje2: em busca de autorias infantis no contexto hospitalar.

A abordagem teórica adotada apoiou-se na perspectiva psicossocial e buscou articular princípios orientadores da teoria históricocultural (VIGOTSKI 2009, 2010) e da teoria das representações sociais (MOSCOVICl, 1978,2012), em diálogo com os estudos sobre narrativa (BRUNER, 1997, 2001, 2002, 2014).

A perspectiva psicossocial consiste na análise multidimensional do processo de produção de sentidos, levando-se em consideração as instâncias de pertencimento transubjetiva, intersubjetiva e subjetiva (JODELET, 2007). Ao considerá-las, intenta-se privilegiar aspectos da cultura institucional, contextos, interações no interior de grupos de pertencimento e o processo de apreensão da realidade pelas individualidades.

1 Trabalho apresentado na disciplina Estágio Supervisionado Específico II: Intervenções em Processos de Saúde e Sofrimento Psíquico do curso de Psicologia da Universidade Federal do Mato Grosso (UFMT). Orientado pela professora Dr.a Daniela Barros da Silva Freire Andrade.

2 Narrativa utilizada como um artefato cultural mediador do contato humano, do diálogo e do desenvolvimento, explorado junto à enfermaria pediátrica, lócus desta pesquisa, onde, por meio do projeto de extensão "Binje: em busca de autorias infantis no contexto hospitalar", procura-se explorar o potencial da narrativa como instrumento psicológico promotor do desenvolvimento da consciência. Suas atividades têm como base a apresentação semanal da história presente no livro Binje (FREIRE, 2013), que aborda a relação do personagem com o adoecimento e com o processo de hospitalização. A mesma se dá na brinquedoteca e nos leitos.
0 atendimento psicoterápico à criança caracterizou-se como lócus promotor de estruturas de oportunidades, para a produção de significações sobre a vivência infantil, relacionada ao abuso sexual e questões decorrentes da relação da criança com a cultura hospitalar.

Considerando a angústia frente ao desconhecido e não nomeado - estranho - e a constatação de que a narrativa possibilita uma forma de interpretar e compreender a realidade, adotou-se, como estratégia psicoterápica, alguns princípios: 1. a narrativa consiste em uma modalidade discursiva capaz de mobilizar significações que transformam o desconhecido, estranho em conteúdo sobre o qual seja possivel anunciar ideias e afetos; 2 . as narrativas produzidas espontaneamente pelas crianças podem ser mobilizadas por repertórios preexistentes nos contextos sociais nos quais as crianças estão inseridas e, a partir do processo de apropriação e reelaboração criativa (VIGOTSKI, 2009) sofrem a ação da internalização, decomposição e recombinação tendo em vista a dimensão criadora do desenvolvimento humano; 3. os enredos que organizam narrativas, socialmente compartilhadas, podem ser interpretados a partir da noção de projeto representacional (BAUER; GASKELL, 1999) este, ao ser compartilhado, repõe algumas significações em detrimento de outras, as mantendo vivas na memória coletiva, de forma a favorecer o processo de mediação com a realidade; 4. a mediação que favorece processos lúdicos, autorais e criativos na produção de sentidos pela criança atua na iminência do desenvolvimento infantil e apresenta potencial terapêutico favorável para a elaboração das vivências associadas à violência contra a criança, podendo ser anunciadas como atividade-guia (PRESTES, 2012), aquela que, potencialmente promove 0 desenvolvimento humano.

0 presente ensaio tem como finalidade investigar o potencial da narrativa enquanto 
instrumento de intervenção capaz de suscitar processos terapêuticos. Tais discussões referendam os estudos a respeito da relevância da narrativa como uma modalidade de comunicação, que possibilita a emergência de processos subjetivos individuais ou grupais, forjando modos de ser e estar no mundo.

\section{Diálogos entre a teoria das representações sociais e a teoria histórico-cultural}

O diálogo estabelecido entre a teoria das representações sociais, elaborada por Moscovici (1978, 2012), e a perspectiva histórico-cultural, que discute o desenvolvimento humano como um fenômeno social, cultural e historicamente construído, proposta por Vigotski $(2009,2010)$, permite compreender o meio como algo circunstancial, suas propriedades objetivas estão intimamente relacionadas à capacidade de apreensão simbólica do ser humano. Nessa qualidade, os atores sociais nele inseridos constroem relações inerentes, aspecto que caracteriza o meio como fonte de desenvolvimento e como instrumento que forja sistemas de interpretação da realidade a partir das trocas, comunicações e interações sociais entre os diferentes sujeitos, grupos e, especialmente, entre gerações (ASSUNÇÃO, 2018).

$\mathrm{Na}$ perspectiva da teoria histórico-cultural, todo processo psíquico possui elementos herdados biologicamente e elementos que surgem na relação e sob a influência do meio, os mesmos devem ser analisados na sua unicidade. O ser em desenvolvimento é aquele que se constitui e é constituído pelo meio, trazendo em si as relações de historicidade, ideologia e representações ${ }^{3}$ compartilhadas no interior de

3 O termo "representações", no contexto deste artigo, faz referência ao conceito "representações sociais" proposto por Moscovici (1978), estas podem ser compreendidas como teorias sociais práticas, cuja função é orientar a formação de condutas e possibilitar co- seus grupos de pertencimento e na sociedade de uma forma geral.

Para Vigotski (2010), o meio ganha contornos a partir dos significados culturais e sociais, delineando um ambiente psíquico, cultural e mental. Logo, as funções psíquicas superiores ${ }^{4}$ emergem com base em processos psicológicos elementares, de origem biológica -estruturas orgânicas -, mas, ao se desenvolverem no contexto relacional, são anunciadas segundo sua dimensão sociocultural.

A natureza social das funções psíquicas superiores possibilita pensar a psique humana como a forma própria de refletir o mundo, entrelaçada com o mundo, a partir das relações da pessoa com o meio mediadas pelos processos comunicacionais.

No entanto, o desenvolvimento humano não se constitui em um simples deslocamento, uma mera transposição, do social para o individual. Considerando a dimensão criativa do desenvolvimento, tem-se que o indivíduo modifica o social, ao alterá-lo em psicológico, ainda em uma relação dialética com o meio, cria a possibilidade do novo.

Desse modo, o meio não é um constructo compreendido como absoluto, mas sim como circunstancial na medida em que se configura em uma relação dialética com as peculiaridades da pessoa, anunciando o que vigotski (2009) chamou de vivência. Na perspectiva vigotskiana, a vivência é caracterizada como motor propulsor do desenvolvimento, a mesma deve ser entendida no âmbito da relação interior do ser humano, que necessariamente envolve o processo de interpretação, atribuição de sentido e mesmo formação de conceito na relação com um ou outro momento da rea-

municações sociais operando no sentido da construção de uma realidade comum a um conjunto social. Representações sociais são saberes do senso comum forjados no compartilhamento de sentidos no interior de um determinado grupo social.

4 Capacidade de planejamento, memória voluntária, imaginação, formação de conceito etc. 
lidade. Segundo tal entendimento, o ambiente só pode ser analisado a partir de sua relação com as especificidades dos indivíduos.

Vivência, enquanto interpretação do vivido dialoga com a noção de situação social de desenvolvimento, constituída por aprendizagens anteriores e forma de significar a realidade nos mais diferentes niveis de tomada de consciência. Logo, é possível anunciar o meio como algo circunstancial atrelado à capacidade de significação do indivíduo. Nesse caso, afirma-se que o abuso sexual, por exemplo, não é significado da mesma forma por crianças e adultos, familiares e equipe de saúde. As significações decorrentes são sensiveis à situação social de desenvolvimento.

Ao pensar a inserção da criança em foco neste artigo e considerar seus diferentes pertencimentos - membro de uma família, aluna, cliente hospitalar, objeto midiático ${ }^{5}$-, é possivel anunciar múltiplas vivências atravessadas por diferentes narrativas, por sua vez orientadas por redes de significações ou famílias de representações sociais convergentes ou divergentes.

De acordo com esses termos, o meio pode ser concebido como uma espécie de fonte de desenvolvimento ou mesmo fonte de produção de sofrimento psíquico. Ao pensar nas práticas de acolhimento às crianças vítimas de abuso sexual, por exemplo, é possivel delinear o que Vigotski (2009) nomeia como "modelo final". Nesse caso, o protocolo de atendimento hospitalar orienta a prática do(a) mediador(a) que interage com o repertório primário das crianças, de tal modo que, graças à ação de internalização, no decorrer do processo, uma determinada ação se constitui como aquisição interna das crianças.

As "forças do meio adquirem significado orientador graças às vivências das crianças,

5 No caso específico tratado neste artigo, o abuso sexual sofrido pela criança foi amplamente divulgado pela mídia. isto é, o estudo do meio se translada em medida significante ao interior das próprias crianças e não se reduz ao estudo das conexões externas de sua vida" (VIGOTSKI, 2009, p. 7).

Ao analisar os contextos de interação, é possivel identificar o acesso das crianças às formas finais - sempre provisórias porque em permanente processo de construção -, apresentadas pela cultura institucional.

A análise do protocolo de atendimento hospitalar à criança vítima de abuso sexual intenta-se destacar as medidas de acolhimento no contexto do processo psicoterapêutico ora anunciado no interior do subprojeto Binje: em busca de autorias infantis no contexto hospitalar.

Binje (FREIRE, 2013) configura-se como uma narrativa cujo enredo privilegia os seguintes eixos temáticos: 1. o hospital segundo a perspectiva da medicina flexneriana e da humanização; 2. o protagonismo da criança hospitalizada; 3. estratégias de enfrentamento psicológico das vivências significadas como ameaçadoras; 4. nomeação de sentimentos; 5 . o cuidado e o autocuidado (TEIBEL, ANDRADE, 2017, 2018; TEIBEL, 2019).

O compartilhamento dessa narrativa, na forma de sessões de contação de história e oficinas socioafetivas, ${ }^{6}$ ao longo de dez anos na rotina de uma enfermaria pediátrica assume, na perspectiva da teoria das representações sociais, o status de uma narrativa que veicula conteúdos sobre e para as crianças hospitalizadas ancorados no paradigma da humanização, impactando as vivências infantis no contexto hospitalar na qualidade de um projeto representacional'7 (BAUER; GASKELL, 1999, TEI-

6 Entende-se por oficinas socioafetivas atividades lúdicas individuais ou grupais que priorizam a elaboração de conteúdos e dos aspectos biopsicossociais vinculados à significação do eu e do outro (ANDRADE, 2019).

7 Por projeto representacional, entende-se a dimensão temporal presente no compartilhamento das representações sociais ancoradas na memória coletiva (passado), negociadas nos grupos de pertencimento (presente) com repercussão na construção do real (futuro). 
BEL, ANDRADE, 2017, 2018), que atua na iminência do desenvolvimento de crianças e adultos envolvidos.

Por conseguinte, sobre o conceito de "zona de desenvolvimento iminente", ${ }^{8}$ Vigotski (2009) atribui importância para a ação colaborativa entre as pessoas como atividade-guia potencializadora do desenvolvimento humano (intersubjetividade), aspecto que destaca a relevância do estudo sobre os contextos de interação uma vez que o mesmo chama a atenção para as relações estabelecidas entre as crianças e seu entorno social.

\section{Um olhar psicossocial para as} vivências infantis e implicações do abuso sexual na infância: um

\section{breve dilucidar}

No escopo deste trabalho, compreende-se que as narrativas apresentadas às crianças no interior do projeto de extensão anunciam formas por meio das quais a cultura hospitalar sinaliza para a criança processos de enfrentamento psicológico da situação traumática.

Especificamente, quando se pensa nas vítimas das diversas formas de violência ou abuso, acolhidas no contexto hospitalar pediátrico, sabe-se que estas, crianças e adolescentes, podem ser afetadas em sua saúde mental. A vivência do abuso sexual impacta no desempenho escolar da criança, bem como na sua sociabilidade, além de afetar seu desenvolvimento orgânico.

Nos casos de abuso sexual intrafamiliar fenômeno de abuso sexual perpetrado contra uma criança em seu espaço doméstico -, específico para este estudo, a família que deve-

8 O uso do termo "zona de desenvolvimento iminente" será aplicado em relação a outras traduções como "zona de desenvolvimento proximal ou imediato", por ele apresentar ao mesmo tempo a ideia de proximidade e possibilidade, como destacou o trabalho de Zoia (2012). ria representar um local seguro para os seus membros, torna-se um espaço de insegurança, medo, desconfiança, conflitos e incertezas. Percebe-se que há uma inversão de papéis, nos quais as crianças ou adolescentes são colocados no lugar de parceiros pseudo-igual no relacionamento sexual e os papéis familiares passam a ser vivenciados de forma desarranjada, malsinando a família como o lugar de crescimento, confiança e apoio, o que poderá resultar em prejuízos ao desenvolvimento de crianças ou adolescentes (FURNISS, 1993; GABEL, 1997; ROMARO; CAPITÃO, 2007).

A maioria das pesquisas revela que o abuso sexual infantil é facilitador para o aparecimento de psicopatologias graves. Os efeitos do abuso na infância podem se manifestar de várias maneiras, em qualquer idade. No que se refere à dimensão social do desenvolvimento, sabe-se que o abuso sexual pode implicar no modo pelo qual as vítimas se relacionam e confiam em outras pessoas.

Flores e Caminha (1994) e Florentino (2015) revelam que as crianças e adolescentes violentados possuem menor "comportamento prósocial: compartilham menos, ajudam menos e se associam menos a outras crianças, quando comparadas com crianças não abusadas. Ainda apresentam retraimento e tendência a estabelecer relacionamentos superficiais" (FLORENTINO, 2015, p. 143, apud Flores e Caminha, 1994).

Os encaminhamentos anunciados na atenção psicossocial voltada para o caso ora analisado levou em consideração: 1. a importância da fala e do processo de significação anunciados, considerando os debates sobre a unidade pensamento e fala nos quais a palavra é signo capaz de representar o objeto na consciência (AGUIAR E OZELLA, 2006), deslocando-se por categorias de significação: sentidos (dimensão mais pessoal, refere-se às singularidades, formas peculiares de apreensão do real) e significados (produções históricas e sociais que 
concorrem ao status de generalização, conceito); 2. a brincadeira como atividade-guia uma vez que cria condições favoráveis para a emergência de neoformações psíquicas, atuando na iminência do desenvolvimento (PRESTES, 2012) de modo a possibilitar tanto vivências associadas à imitação (atividades de reprodução), quanto a imaginação (atividade de criação), 3. a narrativa como modalidade discursiva, instrumento psicológico potencializador da aprendizagem e do desenvolvimento humano.

Sobretudo, a narrativa pode ser considerada veículo para o desenvolvimento social, emocional e intelectual de crianças hospitalizadas. Desse modo, entende-se que a aprendizagem de conceitos relacionados à doença e à hospitalização pode ser mais facilmente trabalhada com a inclusão de atividades lúdicas no hospital, como uma das estratégias facilitadoras do processo de significação infantil, permitindo, dessa maneira, que seus sentimentos sejam expressos, proporcionando uma possível melhora no repertório de enfrentamento dessa condição (SOARES; ZAMBERLAN, 2001). Em outras palavras, o jogo, a história, a músi$\mathrm{ca}$, entre outras formas de atividades lúdicas, podem ser instrumentos de mediação para 0 surgimento de conteúdos espontâneos e compartilhados pelas crianças.

Desse modo, torna-se possivel pensar que o desenvolvimento das formas narrativas exercem um papel de atividade-guia, ${ }^{9}$ posto que, essa atividade conduz fatores fundamentais e contém elementos estruturantes, que compelem o desenvolvimento psicológico e afetivo, gerando neoformações psíquicas, ampliando o processo de significação da realidade, capaz

9 Configura-se enquanto guia posto que está carregada de fatores e elementos que impulsionam o desenvolvimento, favorecendo o estabelecimento de novas relações entre pensamento e ação. A atividade é modificada a cada estágio de desenvolvimento da criança, e para cada conjunto de vivências, de tal forma, que constitui-se enquanto guia para o desenvolvimento psicológico da criança à medida em que produz neoformações psíquicas (PRESTES, 2010). de potencializar formas de tomada de consciência do sujeito (GONÇALVES; SANTOS; ARAGUSUKU; ANDRADE, 2016, p. 154).

A esse respeito, Bruner (1997, 2002, 2014) argumenta que a narrativa não tem necessariamente apenas o compromisso de relatar os acontecimentos copiosamente do modo como ocorreram, mas revela-se como uma metáfora da realidade. Logo, ao narrar, o indivíduo busca conferir interpretações alternativas às experiências explorando seus mundos possíveis, que são familiares, ao abordar os dilemas humanos sob a faceta da imaginação. Assim sendo, as narrativas medeiam a experiência do sujeito e sua relação com o mundo.

Histórias, portanto, não são inocentes: elas carregam uma mensagem implícita à espreita, estão sujeitas a elementos encobertos influenciados pelos modelos culturais daquilo que as individualidades deveriam ou não deveriam ser, de modo que "[...] a construção de si e a narração de si são atividades tão públicas como quaisquer atos privados poderiam ser." (BRUNER, 2014, p. 80).

Assim sendo, para Bruner (2001, 2014), a capacidade de elaborar narrativas possibilita o estabelecimento de processos de diferenciação e indiferenciação com os demais membros da sociedade a partir de sua capacidade de subjuntivar a realidade, como forma de integrar sua perspectiva ao mundo e, desse modo, poder potencializar os processos terapêuticos, visto que é uma prática discursiva que possibilita a expressão do sujeito em sofrimento psíquico que historicamente foi e, ainda nos dias atuais, é silenciado.

Sobre esse aspecto, vale destacar a relação que Bruner (2002) faz sobre texto real e texto virtual. Ao apoiar-se em Iser (1978), o autor anuncia que a relação que o leitor estabelece com o texto real, aqui nomeado de narrativas encorajadoras, permite ao leitor, em um exercício de liberdade de interpretação, a negocia- 
ção de novas possibilidades de texto, ao mesmo tempo que o mesmo elabora sua significação sobre o que está escrito no texto real. Esse processo permite a produção do texto virtual - aquele criado pelo leitor no momento da leitura apoiando-se nas suas estratégias e repertório. Nesse exercício, o leitor transporta para o texto seus conteúdos, buscando acomodá-lo ao que está sendo apresentado pela história, assim como ao seu repertório de concepções sobre a condição humana, criando seu próprio mundo pessoal de modo a integrar de forma socialmente aceitável, sua história de vida e identidade.

Desse modo, observa-se a criação de narrativas autodescritivas envolvendo não apenas a capacidade de construção da mesma, mas de sua compreensão desse processo. Tal vivência permite a elaboração de um nivel de consciência ampliado por meio do qual a criança consegue elaborar sua identidade e "sentir-se em casa no mundo".

A relação entre texto real e virtual pensada na perspectiva vigotskiana sugere destacar as duas dimensões do desenvolvimento humano reprodução e criação. Nesse exercício, é possível destacar a capacidade do sujeito em reproduzir e compartilhar significações em seu grupo de pertencimento - dimensão reconstituidora ou reprodutiva do desenvolvimento, mas também de questionar determinadas representações sociais, crenças, valores, entendendo a existência de diferentes perspectivas possiveis e construindo, por meio da reelaboração criativa, sua própria perspectiva ao vislumbrar um lugar para seu mundo pessoal que integre sua história de vida e significação de si - dimensão criativa do desenvolvimento humano.

\section{Metodologia}

A metodologia empregada para o processo de produção de dados foi inspirada na aborda- gem microgenética (GOÉS, 2000), por meio da qual se procedeu o delineamento de recorte de episódios interativos, sendo o exame orientado para o funcionamento dos sujeitos focais, as relações intersubjetivas e as condições sociais da situação, resultando num relato minucioso dos acontecimentos. Desse modo, foram destacados, para efeitos deste artigo, três episódios provenientes das sessões de psicoterapia com uma criança, nomeada $\mathrm{V}^{10}$ Os mesmos se deram considerando os atendimentos individuais e grupais, realizados no leito, refeitório e brinquedoteca. Os relatos da avó da criança, e as interlocuções junto à equipe multiprofissional e Equipe Multiprofissional de Atenção à Criança (Emac) do HUJM também auxiliaram no delineamento da análise empreendida.

Em atenção ao atendimento com criança, no trabalho de entrada e permanência em campo, a mediadora adotou a postura de adulto atípico (CORSARO, 2005; 2011), que considera o grau e a natureza da aceitação e participação da mesma pela criança. Com base nessa perspectiva, a mediadora deve ser aceita pela criança como uma "amiga adulta", considerada membro e participante, e que, se comparado com os outros adultos, demonstra pouca ou nenhuma autoridade por destituir-se do papel de controle e regulação das ações das crianças, exercido por adultos típicos, frequentemente ativos e controladores.

Os encontros havidos foram orientados segunda a noção de narrativas encorajadoras, ${ }^{11}$

10 A criança será nomeada a partir da letra V., enquanto atribuição de nome fictício, ao ser citada no decorrer da apresentação. A escolha, remete a primeira letra da palavra vermelho, cor estimada pela paciente. A criança assumia, ao longo das sessões, o vermelho para ela e o laranja para a mediadora. A mediadora, na primeira sessão, disse que o laranja era a sua cor preferida, enquanto que a $\mathrm{V}$. disse ser a vermelha sua cor apreciada. A partir disso, a todo momento que a criança produzia alguma narrativa, diferenciava o desenho e os trabalhos em cores vermelho e laranja.

11 Refere-se aqueles que estão abertos à imprevisibilidade e apresentam o potencial de estimular a criação de novos enredos, perante a apresentação de uma narrativa semiestruturada, baseada na utilização de 
(GONÇALVES; SANTOS; ARAGUSUKU; ANDRADE, 2016), compreendidas em sua possibilidade de estimular a criação de novos enredos a partir da apresentação de uma narrativa inicial e semiacabada, que encoraje sua continuidade pautada pelas dimensões criativa e reprodutiva (VIGOTSKI, 2009) do comportamento humano, ao buscar diminuir a pressão normativa que com frequência ocorrem nas situações usuais de interlocução entre adultos e crianças.

No caso específico da enfermaria pediátrica, lócus do atendimento psicoterápico, considera-se o compartilhamento da narrativa Binje (FREIRE, 2013) pela personagem Dr.a Ana Tsuru, uma médica brincalhona que se veste de um jaleco branco com pássaros estampados nos bolsos. A médica conversa com as crianças na companhia de um guarda-chuva e uma bolsa repleta de materiais, ambos da cor amarela anunciada como metáfora da cor do sol em referência ao que existe no mundo para além das paredes brancas do hospital. Frequentemente, os conteúdos das personagens Binje e Dr.a Ana Tsuru são anunciados pelas crianças em sessões de atendimento psicoterápico individual, aspecto que possibilita a análise da narrativa institucional na iminência dos processos de significação das vivências infantis.

Ainda se explora a narrativa compreendida como potencializadora do processo de metaforização, apoiando-se em Gauthier (2004, 2003), que destacou a relevância das questões que induzem operações mentais de metaforização da vida.

Desse modo, as intervenções realizadas foram registradas no Caderno de Campo, o corpus foi organizado na forma de episódio levando em consideração o conteúdo semântico, recorrência e a carga afetiva empreendida nos processos comunicacionais, de modo a delimi-

ferramentas mediadoras de interações sociais, tais como filmes, imagens, situações problemas, músicas, pequenas histórias, dentre outras (GONÇALVES; SANTOS; ARAGUSUKU; ANDRADE, 2016, p. 154). tar episódios emblemáticos que foram interpretados a partir da análise compreensiva.

\section{Caracterização da criança}

A fim de evidenciar algumas particularidades da criança, serão apresentadas informações, no entanto, respeitando o limite de aproximação com sua identidade.

Criança V., 6 anos, vítima de abuso intrafamiliar cometido pelo tio paterno durante uma festa em família, na casa de sua avó, fundo da casa onde residia com a família, incluindo pais e irmãos. No hospital, estava acompanhada da avó materna, com quem residiria após o trauma, e quem a criança escolhera ser assistida.

Para o caso, compreende-se que não seja possivel dimensionar o impacto, ou os prejuízos que poderão surgir a partir desse fator complicador, no entanto, sabe-se que a idade da criança poderá interferir no tipo de comprometimento que ela poderá desenvolver tendo em vista sua situação social de desenvolvimento. Algumas evidências apontam que quanto maior for o período de tempo de abuso, por exemplo, maior também será o surgimento de consequências indesejáveis. Nos casos de vínculo entre o abusador e a vítima, outro fator que compromete as consequências é a qualidade dessa relação existente.

A criança encontrava-se bastante ferida, com vários hematomas em sua pele por conta da tamanha violência sofrida. A mesma foi submetida a cirurgia, internação no Hospital e Pronto Socorro Municipal da capital (HPSMC), precedendo sua internação junto ao HUJM, ainda, com exames de ultrassom abdominal identificado grande acúmulo de fezes presas em seu intestino, além de apresentar episódios de vômitos, dores e ansiedade extrema.

V. apresentava-se assustada e retraída, seus gestos anunciavam tensão e tendência a autoproteção, a criança procurava proteger o 
corpo nos primeiros momentos em que a mediadora esteve com ela, esforçando-se em deixar as pernas bem encaixadas, fechadas e os braços junto ao corpo.

\section{Do texto real ao texto virtual: a} metáfora da vida e seus mundos possíveis pela criança

A análise deste estudo de caso será subdividida de acordo com três episódios elaborados a partir dos conteúdos gerados ao longo de seis sessões, a saber: 1. a metáfora do ninho como princípio orientador do pensar e do sentir; 2 . a metáfora da bolsa e a reinvenção do eu; 3 . a metáfora das cores como estratégia de enfrentamento e representação de si.

\section{Episódio 1. A metáfora do ninho} como princípio orientador do pensar e do sentir

No primeiro episódio, a mediadora utilizou seu jaleco branco, como praxe, descaracterizado com um boton de Tsurus ${ }^{12}$ colorido ao bolso e a tiracolo segurava uma bolsa amarela ${ }^{13}$, parecida com a da Dr.a Ana Tsuru repleta de materiais que permitiam a expressão plástica da criança. Primeiramente, viu a criança pelo espaço de vidro localizado ao cento da porta em seu leito. Procurou enxergá-la não a partir das lesões em seu corpo (sinais de arranhões na pele, lesões nos olhos, hematomas, cicatrizes e cortes principalmente na região do pescoço e cabeça. Assim, procurou estar com V. a seu modo e no seu tempo.

12 Este broche fazia referência à narrativa da Dr.a Ana Tsuru, amplamente compartilhada no interior do projeto de extensão intitulado Binje: em busca de autorias infantis no contexto hospitalar, desenvolvido pelo Grupo de Pesquisa em Psicologia da Infância (GPPIN).

13 A bolsa amarela chamou a atenção de V. e mobilizou o planejamento de estratégias com vistas ao atendimento psicoterápico que ensejou os conteúdos relatados no episódio 2 intitulado: "A metáfora da bolsa e a reinvenção do eu".
Adentrou ao quarto, aos poucos, sem se fazer notar, aliada ao cuidado e sutileza, necessários a um primeiro encontro.

Com um espaço curto de tempo, agora, no esforço de um diálogo introdutório, apresenta-se como mais uma nova amiga no hospital.

A mediadora diz se sentir preocupada com a sua condição e que tinha em comum, o desejo de ajudá-la assim como os demais profissionais daquele espaço.

Assegurou-se à necessidade de que esse primeiro encontro fosse elaborado no sentido de possibilitar o encontro com a mesma, assumindo tal experiência refinado à captura e a escuta das diferentes expressões infantis, concebendo a criança com a qualidade de um informante autêntico.

No trabalho de entrada e permanência em campo para tal atendimento, desde o início, adotou-se a postura de adulto atípico (CORSARO 2005; 2011). E com essa finalidade, salientou-se a concepção ativa compartilhada entre adulto e criança, permitindo que esta última pudesse exercer postura proativa e coparticipativa na presente relação.

Adotar tal postura não significou, contudo, que a mediadora se eximiria de qualquer intervenção, mas foi empregada no sentido de empenhar-se diante do exercício de estar diante da criança vislumbrando um encontro menos hierarquizado, no qual a negociação entre gerações fosse tomada como princípio prioritário.

A mediadora a partir deste exercício, ao começar sua mediação, cantarola uma música pela qual a letra conversa com passarinhos, e em tal caso, a menina constrói sua primeira narrativa - o ninho - estimulada a mencionar quais as principais fontes de informação que apoiou a construção da narrativa. Como fundamento, foi solicitado que a criança discorresse sobre os aspectos que considerava importantes, com o propósito de investigar a di- 
mensão expressiva, orientada pela focalização do sujeito, que compõe a relação da criança com o objeto social, demonstrando os conteúdos e sentidos específicos eleito pela vítima sobre o mesmo.

A criança constrói um ninho com o apoio de diversos materiais - argola, fitas, durex colorido e origamis de Tsurus -, acrescentando ao mesmo passarinhos e ovinhos, com o auxílio da mediadora. A mesma indaga o que estariam fazendo os passarinhos no ninho. A criança responde que, um passarinho estava gritando e chorando. Indagada como ele se sentia e ela responde "com medo, ele tava sozinho, gritava, mas o pai dele num ouviu".

Continua o diálogo sobre quem eram eles e porquê o passarinho gritava e sentia medo. "A mamãe do passarinho foi busca comida pra eles, o pai foi pra nuvem, saiu do ninho. 0 passarinho tinha ido buscá laranja". A criança complementa, diz tratar-se dos pais do passarinho e os irmãos, "o passarinho tava com medo da nuvem má que tava chegando e queria pegá o passarinho".

A mediadora então questiona o que aconteceu, o que tinha na nuvem, pois percebe que era importante notar como ela elaboraria o desfecho da narrativa. V. continua "a nuvem era má, fazia maldades. Ela não pegou o passarinho. o pai do passarinho foi nele, (...) no passarinho e levou ele voando". E, nesse momento, V. silencia-se.

Ao final, a mediadora pergunta para criança onde guardar o ninho. Ela escolhe o criado mudo ao lado de sua cama. E assim foi deixado. "Esses passarinhos precisam ficar bem seguros, e acho que aqui eles estarão", afirma a mediadora.

No mesmo dia, a equipe relata a mediadora sobre os cuidados médicos e tratamento da criança em questão. Ela chegou a ter prejuízos em seu útero, seu interior havia sido muito machucado, havendo necessidade de realiza- ção de cirurgias, inclusive optando pelo uso de uma sonda.

A equipe também trouxe a informação de que a criança não defecava há vários dias após o ocorrido, e que a preocupação era com relação a uma nova e arriscada cirurgia para solucionar o caso. Importante mencionar que diante desse caso clínico, após a primeira sessão de psicoterapia com a criança quando se deu a elaboração da narrativo do ninho, V. defecou pela noite.

Neste episódio, percebe-se o potencial do processo de metaforização espontânea elaborado pela criança, apoiando-se em narrativas preexistentes de modo a propiciar não apenas o relato dos acontecimentos, mas sim a sua interpretação sobre o vivido, possibilitando, no nível simbólico, algum controle sobre a situação, impedindo no âmbito da imaginação que $o$ ato violento fosse consumado tendo em vista o sentido de proteção atribuído a figura paterna. Nesse processo de significação, a realidade tornou-se segura e passivel de confiança, relaxar foi possivel.

\section{Episódio 2. A metáfora da bolsa e a reinvenção do eu}

Após a elaboração da narrativa do ninho por V., percebeu-se que a criança já se apresentava mais tranquila, tônus muscular menos tensionado. Neste segundo encontro, a mediadora havia levado uma bolsa amarela para V., parecida com a que ela havia levado com os materiais para ela se expressar no primeiro encontro. Desta vez, aquela bolsa poderia ser sua própria bolsa, poderia enfeitá-la como quisesse. No dia anterior, a mediadora, ao observar o interesse da criança pela bolsa, perguntou se ela gostaria de uma bolsa como a que usava e que cor gostaria. V., apesar de se autoatribuir a cor vermelha, na ocasião, optou pela cor amarela. 
V. procurou guardar os materiais dentro da bolsa e se dedicou em fazer um ninho na nova bolsa, utilizando fitas e cores vermelha (autoatribuída) e laranja (cor atribuída à mediadora).

V. e mediadora operaram juntas na confecção do ninho, aos poucos V. foi anunciando que o ninho da bolsa amarela seria laranja e os ovinhos do ninho seriam vermelho, rosa (atribuída à avó) e azul (cor não atribuída à pessoa), depois introduziu o verde representando a mãe. Algumas fitas foram unidas e amarradas em torno do ninho. Havia preocupação de V. em unir as alças da bolsa como se quisesse fechá-la, protegê-la.

Ao admirar o ninho na bolsa e apresentá-lo para sua avó, v. parecia estar elaborando, na relação com a mediadora, conteúdos associados ao seu desejo de continência e proteção, um lugar de afeto como o ninho, ao mesmo tempo frágil e seguro, um lugar possivel para a constituição do seu eu na relação com o outro.

\section{Episódio 3. A metáfora das}

\section{cores como estratégia de}

\section{enfrentamento e representação de si.}

A questão das cores vermelha e laranja se constituiu como conteúdo emblemático que constantemente apareceu durante os episódios. A criança procurava destacar as cores nas tintas, fitas, argolas, durex, principalmente enquanto confeccionou o ninho e pintou a bolsa. Inclusive, no último episódio sabendo que não voltaria a ver a mediadora por conta de sua alta anunciada, V. acrescentou uma fita vermelha no boton que a mediadora costumava utilizar e entregou um ninho, outro ninho, que havia feito durante o tempo que a mediadora não estava com ela. $O$ ninho feito por V. foi anunciado como um presente de despedida.

Nesta sessão, V. brincou com as fitas de cetim. Esticou as fitas vermelha e laranja por todo o quarto, depois guardou a fita laranja com ela e em seguida enrolou a mediadora com a fita vermelha.

Demonstrou muita satisfação, alivio, quando soube que ela poderia ficar com a bolsa e com tudo que tinha dentro - materiais que ela utilizou durante o atendimento psicoterápico. Com o costume de guardá-los dentro da bolsa, colou vários laços de fitas na mesma e procurava deixá-la fechada, amarrada, tornando possível perceber a bolsa enquanto uma representação de seu corpo.

V. entrelaça suas pernas ao corpo da mediadora, agora as pernas não estavam mais tensas e fechadas - os esparadrapos, as suturas, eles já haviam sido retirados. V. estava sem a sonda, mais relaxada, sentia-se protegida. $\mathrm{E}$ assim permaneceu parecendo se sentir segura.

Nota-se neste episódio o movimento expansivo das fitas vermelha e laranja ocupando o espaço da enfermaria ao mesmo tempo que, por meio da fita vermelha, V. demarca seu espaço/lugar no jaleco da mediadora. 0 ninho e a bolsa, assim como a mediadora, assumem o status de referência para o começo de novos voos.

Tais episódios revelam núcleos de sentidos em um processo por meio do qual se forja um cenário lúdico de cuidado, incomum no contexto de tratamento intensivo, demarcado como um espaço simbólico da expressão infantil. Em adição, pode-se destacar a elaboração de significados a partir do texto real, narrativas encorajadoras, permitindo a produção espontânea de metáforas, que contribuíram para a construção de enredos sobre a vivência relacionada ao abuso sexual e a hospitalização da criança - texto virtual.

Destaca-se ainda a construção de vínculos que fomentaram uma aliança terapêutica com a criança, apresentando-se como um canal eficaz de comunicação e ressignificação da relação eu-outro. 
A análise dos episódios releva o potencial de construção sociocognitiva da realidade presente nos processos narrativos, bem como anunciam a coordenação de metáforas como estratégia de simbolização e condensação de sentidos capaz de operar na tomada de consciência de si. Tais vivências permitem anunciar intervenções terapêuticas como atividades guias que promovem a iminência do desenvolvimento mesmo e, especialmente, em condições muito adversas.

\section{Considerações finais}

0 estudo ora empreendido permite revelar o impacto do uso da narrativa encorajadora como modalidade discursiva que opera no processo de interpretação da realidade. Em especial, destaca-se o valor da mediação semiótica em contexto psicoterapêutico marcado pela construção de uma relação de confiança interpessoal, condição que gerou oportunidades para a produção espontânea de metáforas condensadoras de sentidos pela criança em questão.

0 processo de atendimento psicoterapêutico, mediado por uma narrativa encorajadora, ainda favoreceu o desenvolvimento das funções simbólicas - produção do texto virtual, modo de subjuntivar a realidade - e dos processos comunicacionais apoiado no uso de múltiplas linguagens - oral, corporal e plástica. Tais processos promoveram o acesso às vivências infantis associadas à sua condição de vítima de abuso sexual, ajudando na externalização de conflitos associados ao medo, insegurança e perda de confiança em seus pares, além da ruptura com o senso de realidade.

Além de permitir a verbalização dos conteúdos ansiogênicos, a mediação semiótica, pela via da narrativa e pelo processo de metaforização, atuou como estratégia de enfrentamento psicológico, possibilitando o surgimento de novas significações sobre a relação eu-outro ancoradas na noção de confiança e continência, bem como permitiu a produção de maior grau de tomada de consciência sobre a situação vivenciada, mudando a situação social de desenvolvimento da criança.

Assim, a partir da análise episódica, identificou-se o potencial da narrativa compreendida como metáfora da vida presente no processo de significação acerca do abuso sexual pela criança.

As vivências no interior do processo psicoterapêutico, apoiadas em narrativas preexistentes anunciadas como narrativas encorajadoras ou semiacabadas, revelaram repertório de significados que, ao serem internalizados pelas crianças, foram decompostos e recombinados em seu exercício de reelaboração criativa e produção de sentidos. Continência, imitação e criação, elementos presentes no contexto de interação psicoterápica atuaram na iminência do desenvolvimento infantil e contribuíram para a significação do vivido.

Nesse sentido, nota-se uma disposição da criança em organizar a experiência segundo uma estrutura narrativa, atividade crucial para as interações sociais, inseparável e constitutiva da vida cultural.

As metáforas do ninho e das cores permitiram, dessa maneira, que, em algum nível, os sentimentos e pensamentos da criança fossem expressos, proporcionando uma possivel ampliação no repertório de enfrentamento de sua condição. Em outras palavras, a narrativa pode ser um instrumento de mediação para o surgimento de conteúdos espontâneos e compartiIhados pelas crianças.

Sendo assim, torna-se possivel pensar que as narrativas podem atuar como atividadeguia, posto que, essa atividade conduz fatores fundamentais e contém elementos estruturantes, que compelem o desenvolvimento psicológico e afetivo, gerando neoformações psíquicas, ampliando o processo de significação 
da realidade, capaz de potencializar formas de tomada de consciência, com destaque ao ato lúdico em contextos de interação, os quais crianças e adultos vivenciam condições para que a primeira possa desenvolver, sua versão da realidade, com baixa pressão normativa e liberdade para criar novos sentidos.

Essa perspectiva de acolhimento é possivel quando ancorada em uma cultura institucional orientada pelo paradigma da humanização no atendimento à saúde.

\section{Referências}

AGUIAR, Wanda Maria Junqueira; OZELLA, Sergio. Núcleos de significação como instrumento para a apreensão da constituição dos sentidos. Psicologia, Ciência e Profissão, Brasília, v. 26, n. 2, p. 222-245, 2006. Disponivel em: http:// www.scielo.br/scielo.php?script=sci_arttext\&pi$d=S 1414-98932006000200006 \& \operatorname{lng}=e n \& n r m=i s o$ Acesso em: 6 fev. 2020.

ANDRADE, Daniela Barros da Silva Freire. Rede de Apoio à Infância: interfaces com a Psicologia e Pedagogia. Projeto de Extensão, Sistema de Extensão (SIEX). Coordenação de Extensão (CODEX). Universidade Federal de Mato Grosso. Cuiabá, 2019.

ASSUNÇÃO, Andréia Maria de Lima. Representações sociais sobre profissionais de saúde segundo crianças: implicações identitárias no contexto da hospitalização pediátrica. 2018. 247 f. Dissertação (Mestrado em Educação) - Universidade Federal de Mato Grosso, Instituto de Educação, Cuiabá - MT, 2018. Disponível em: https://www1.ufmt.br/ufmt/un/publicacao/ ppge?busca=crian\%C3\%A7as+hospitalizadas\&filtro=chave\&categoria=. Acesso em: 3 jul. 2019.

BAUER, M. W.; GASKELL, G. Towards a paradigm for research on social representations. Tradução de Eliza Moura. Journal for the Theory of social behavior. v. 29, n. 2, p. 163-186, 1999.

FREIRE, Daniela. Binje. Cuiabá: EdUFMT, 2013.

BRUNER, Jerome. Fabricando histórias: Direito, literatura, vida. Tradução Fernando Cássio. São Paulo:
Letra e Voz, 2014.

BRUNER, Jerome. Realidade Mental, Mundos Possíveis. Tradução Marcos A. G. Domingues. São Paulo: Artmed, 2002.

BRUNER, Jerome. A cultura da Educação. Tradução de Marcos A. G. Domingues. Porto Alegre: Artmed, 2001.

BRUNER, Jerome. Atos de Significação. Tradução Sandra Costa. Porto Alegre: Artes Médicas, 1997.

CORSARO, Willian Arnold. Sociologia da Infância. Tradução Lia Gabriele R. Reis. Porto Alegre: Artmed, 2011.

CORSARO, Willian Arnold. Entrada em campo, aceitação e natureza da participação nos estudos etnográficos com crianças pequenas. Educ. Soc., Campinas, v. 26 , n. 91 , p. 443-464, maio/ago. 2005. Disponivel em: http://www.scielo.br/pdf/es/v26n91/ a08v2691.pdf. Acesso em: 23 jun. 2018.

FLORENTINO, Bruno Ricardo Bergámo. As possiveis consequências do abuso sexual praticado contra crianças e adolescentes. Fractal, Rev. Psicol. Rio de Janeiro, v. 27, n. 2, p. 139-144, Ago. 2015. Disponível em: http:// www.scielo.br/scielo.php?script=sci_arttext\&pid=S1984-02922015000200139\&lng=en\& $n r m=i s o$. Acesso em: 6 fev. 2020.

FLORES, Renato Zamora.; CAMINHA, Renato Maiatto. Violência sexual contra crianças e adolescentes: algumas sugestões para facilitar o diagnóstico correto. Rev. psiquiatr. Rio Gd. Sul, v. 16, n.2, p. 158-67, maio-ago, 1994. Disponivel em: http://bases.bireme.br/cgibin/wxislind.exe/iah/online/? IsisScrip$\mathrm{t}=\mathrm{iah} / \mathrm{iah} . \mathrm{xis} \& \mathrm{src}=$ google \& base=ADOLEC\&lang=p\&nextAction $=$ lnk \&exprSearch $=173725 \&$ indexSear ch=ID. Acesso em: 6 fev. 2020.

GAUTHIER, Jacques Zanidê. A questão da metáfora, da referência e do sentido em pesquisas qualitativas: o aporte da sociopoética. Rev. Bras. Educ., Rio de Janeiro: n. 25, p. 127-142, jan./ fev./ mar./ abr., 2004. Disponivel em: http://www.scielo.br/pdf/rbedu/ n25/n25a11.pdf. Acesso em: 18 jun. 2018.

GAUTHIER, Jacques Zanidê. Metáfora e conceito em pesquisas qualitativas. Revista Enfermagem. UERJ, Rio de Janeiro: n. 11, p. 301-307, 2003. Disponível em: http://www.facenf.uerj.br/v11n3/v11n3a11.pdf. 
Acesso em: 18 jun. 2017.

GÓES, Maria Cecília Rafael. A abordagem microgenética na matriz histórico-cultural: uma perspectiva para o estudo da constituição da subjetividade. Caderno Cedes [online], vol. 20, n. 50, p. 9-25, abril, 2000. Disponível em: http:// www.scielo.br/scielo.php?script=sci_arttext\&pi$d=$ S0101-32622000000100002 \&lng=en \& nrm=iso. Acesso em: 10 fev. 2020.

GONÇALVES, Naiana Marinho.; DOS SANTOS, Ruzia Chaouchar.; ARAGUSUKU, Henrique Araujo.; ANDRA$D E$, Daniela Barros da Silva Freire. Narrativa e novas formas de cuidado em saúde mental. Cadernos Brasileiros de Saúde Mental, Brazilian Journal of Mental Health, vol. 8, n. 20, p. 157-180, dezembro 2016. Disponivel em: http://incubadora.periodicos.ufsc. br/index.php/cbsm/article/view/3949/4792. Acesso em: 7 fev. 2020.

JODELET, Denise. Imbricações entre representações sociais e intervenção. In: MOREIRA, A. S. P.; CAMARGO, B. V. (Org.) Contribuições para a teoria e o método de estudo das representações sociais. João Pessoa: Editora Universitária da UFPB, p. 45-74, 2007.

MARTINS, Lígia Márcia.; RABATINI, Vanessa Gertrudes. A concepção de cultura em Vigotski: contribuições para a educação escolar. Revista Psicologia Política, 11(22), p. 345-358, 2011. Disponível em: https://dialnet.unirioja.es/servlet/articulo?codigo=3899064. Acesso em: 6 fev. 2020.

MOSCOVICl, Serge. A psicanálise, sua imagem e seu público. Tradução Sonia Fuhrmann. Petrópolis, RJ: Vozes, 2012.

MOSCOVICI, Serge. A representação social da psicanálise. Rio de Janeiro, Zahar, 1978.

PRESTES, Zoia. Quando não é quase a mesma coisa: traduções de Lev Semionovith Vigotski no Brasil. Campinas, SP: Autores Associados, 2012.

ROMARO, Rita Aparecida.; CAPITÃO, Claudio Garcia. As faces da violência: aproximações, pesquisas, reflexões. São Paulo: Vetor, 2007.

SOARES, Maria Rita Zoéga.; ZAMBERLAN, Maria Aparecida Trevisan. A inclusão do brincar na hospitalização infantil. Estud. psicol. (Campinas), Campinas, v. 18, n. 2, p. 64-69, agosto, 2001. Disponível em: http:/ / www.scielo.br/scielo.php?script=sci_arttext\&pid=S0103-166X2001000200006\&lng=en \& nrm=iso. Acesso em: 5 fev. 2020.

TEIBEL, Érica Nayla Harrich. Narrativa como mediadora de vivências infantis no contexto hospitalar: as representações sociais sobre o cuidado em uma enfermaria pediátrica, segundo equipe de saúde e as significações infantis. 2017. 239 f. Tese (Doutorado em Educação) -Universidade Federal de Mato Grosso, Instituto de educação, Cuiabá - MT, 2017. Disponível em: https://sucupira.capes.gov.br/sucupira/public/consultas/coleta/trabalhoConclusao/ viewTrabalhoConclusao.jsf?popup=true\&id_trabalho=5007796. Acesso em: 10 dez. 2019.

TEIBEL, Érica Nayla Harrich.; ANDRADE, Daniela Barros da Silva Freire. Narrativas de e para crianças: sobre compartilhamentos de representações sociais no contexto do cuidado hospitalar infantil. In: PASSEGI, Maraia da Conceição; DEMARTINI, Zeila de Brito Fabri; NOVAES, Adelina Oliveira (orgs.). Infâncias, juventudes, universos (auto)biográficos e narrativas. Curitiba: Editora CRV, 2018. p. 199-214.

TEIBEL, Érica Nayla Harrich.; ANDRADE, Daniela Barros da Silva Freire. Intervenção em práticas de cuidado à criança no contexto hospitalar: representações sociais da equipe de saúde. Psicologia e Saber Social, 6(1), p. 87-100, 2017. Disponível em: http:// www.e-publicacoes.uerj.br/index.php/psi-sabersocial/article/view/30668. Acesso em: 10 fev. 2020.

VIGOTSKI, Lev Semyonovich. Quarta aula: a questão do meio na Pedologia. Tradução de Márcia Pileggi Vinha. Psicologia USP, São Paulo, v. 21, n. 4, p. 681701, 2010. Disponível em: http:/ / www.revistas.usp.br/ psicousp/article/view/42022. Acesso em: 12 set. 2019.

VIGOTSKI, Lev Semyonovich. Imaginação e criação na infância: ensaio psicológico: livro para professores. Apresentação e comentários de Ana Luiza Smolka. Tradução de Zoia Ribeiro Prestes. São Paulo: Ática, 2009.

Recebido em: 15/02/2020

Revisado em: 04/08/2020 Aprovado em: 08/08/2020 
Milene Gabriela Winck mestranda do Programa de Pós-Graduação em Educação da Universidade Federal do Mato Grosso (UFMT) campus Cuiabá (MT). Bolsista da Coordenação de Aperfeiçoamento de Pessoal de Nível Superior (Capes), membro do Grupo de Pesquisa em Psicologia da Infância (GPPIN).E-mail: milenewinckpsicologia@gmail.com

Daniela Barros da Silva Freire Andrade é doutora em Educação pela Pontifícia Universidade Católica de São Paulo (PUC -SP). Professora associada da Universidade Federal do Mato Grosso (UFMT) campus Cuiabá (MT), atuando no Programa de Pós-Graduação em Educação e no curso de Psicologia. Pesquisadora do Centro Internacional em Representações Sociais e Subjetividade - Educação (CIERS-Ed). Coordenadora do Grupo de Pesquisa em Psicologia da Infância (GPPIN). E-mail: freire.d02@gmail.com 